\title{
CONCEPÇÕES SOBRE O "OLHAR A REGIÃO" E MÉTODOS FILOSÓFICOS E DE PESQUISAS
}

\author{
Livio Andrade Wanderley \\ Doutor em Administração (FGV/SP) \\ Professor do Programa de Pós Graduação em Economia da Universidade Federal da Bahia \\ (PPGE/UFBA), Bahia, BA, Brasil. \\ livio@ufba.br
}

\begin{abstract}
RESUMO - Faz-se uma reflexãosobre o conceito de região sob os pontos de vistas filosóficos, metodológicos, e da interpretação e intervenção do agente econômico. Contémum esboço sobre o positivismo, historicismo e marxismo, ancorando a formulação de modelos científicos de objetividade. Abordou-seo método situando-o na filosofia e na metodologia de pesquisa.O "olhar a região" e a forma de intervenção baseia-se em modelos natural ou social de objetividade científica, segundo os conceitos, de região "objeto"e"sujeito". Deduziu-se que a intervenção sob um olhar objeto produziu um desenvolvimento assimétrico entre regiões, enquanto que imbuído de um olhar sujeitobusca-seatenuar essas assimetrias.
\end{abstract}

PALAVRAS CHAVES:Filosofia; Método;Economia Regional.

\section{DESIGNS ON THE "LOOK THE REGION" METHODS AND PHILOSOPHICAL AND RESEARCH}

\begin{abstract}
A reflection is made on the concept of region under the philosophical, methodological, and interpretative views of the economic agent. It contains a sketch on positivism, historicism and Marxism, anchoring the formulation of scientific models of objectivity. The method was approached by placing it in the research philosophy and methodology. The "look at the region" and the form of intervention is based on natural or social models of scientific objectivity, according to the concepts of "object" and "subject" region. It was deduced that the intervention under an object look produced an asymmetric development between regions, while imbued with a subject look to attenuate these asymmetries.
\end{abstract}

KEY WORDS: Philosophy; Method;Regional Economy

\section{INTRODUÇÃO}

Desenvolve uma reflexão sobre o "olhar a região" através de pontos de vista filosóficos, da escolha do método de investigação científica e da percepção do olhar a região objeto ou sujeito. Como ponto de partida apoia-se em Löwy (1987), abordandoleiturasdiversasvisandoà busca do saber e do conhecimento da natureza e da sociedade, no âmbito da filosofia da ciência e de posicionamentos 'positivista, historicista e marxista.Sistematiza-seo método através de suas clivagens filosóficas e da investigação científica, e faz-se um enquadramento do olhar a região pelo pesquisador segundo os fatos e valores.Quanto à apreensão da realidade objetiva, resenham-se os aspectos das (in) existênciasde condicionantes, similaridades e posicionamentos entre as condições da natureza física (leis naturais), da contextualização social e seu processo histórico (leis sociais) e de processos de produção (leis econômicas). Refletindoo"olhar a 
região"através de modelos de objetividade científica ancorados em leis da natureza e da sociedade, faz-se uma abordagem das percepções de região objeto e sujeito.

Os linksentre fatos e valores colocamo analista regional na busca de modelos de percepção e compreensão da região,segundo afinidades ou independência entre as leis naturais e econômicas.Reconhece-se que em qualquer estudo a posição do analista regional é condicionada por modelos de objetividade científica, os quais definemo olhar e a forma de intervenção na região, segundo o ponto de vista de "objeto" ou de "sujeito". Imbuído nos princípios do possibilismo geográfico, a concepção sobreo "olhar a região" sempre foi baseada no conceito de região objeto. Diante dosatuais padrões tecnológicos, processos produtivos, estruturas de mercados, relações sociais, etc., concebe-sea necessidade de uma região organizadapautando-se pela qualidade no funcionamento de suas instituições ede relações socioeconômicas e políticas, resultantes de padrões culturais, de sua formação histórica e da evolução social.

Dessa forma, cada região tem sua dinâmica própria e peculiar tal que propicia a reflexão de duas questões: 1)a regiãosendo interpretada como objeto, a intervenção do agente econômico tem provocadoum desenvolvimento socioeconômico assimétrico entre as regiões;2) a região sendo concebida como sujeito, propicia uma afinidade entre as intervenções do agente com a sociedade, atenuando desequilíbrios regionais.A análise desses argumentos baseia-se nas nos fundamentos filosóficos e metodológicos que determinam a qualidade da intervenção, sob as óticas de regiões objeto e sujeito.

\section{UM ESBOÇO DE CORRENTES FILOSÓFICAS}

Com a finalidade de contextualizar modelos de objetividade científica, é apresentado um esboço de posições filosóficas no trato da realidade objetiva. Com base em Löwy (1987), esta seção faz uma síntese sobre as correntes positivistas, historicistas e marxistas.

O positivismoapoia-seem dois supostos: anaturalização das ciências sociaiseaneutralidade axiomática do saber. Dessa forma, é concebida uma harmonia natural da sociedade que fica isenta de padrões normativos e de juízos de valores; neste sentido, o positivismo trata do que é, era ou será diferentemente de concepções normativas fundamentadas em sistemas de valores ancorados em atributos ideológicos, culturais, políticos e religiosos, e que tratam, portanto, do que deve ser, deveria ser ou deverá ser. O pensar positivo com as leis sociais e econômicas harmonizadas com as leis naturais, negligencianormas pré-definidas baseadas em juízos de valores.A sua formulação foi contextualizadaem dois grandes momentos históricos:um "revolucionário" e outro "conservador", mas sustentados nos mesmos conceitos, emborautilizados em sentidos opostos. 
O primeiro recorte histórico foi referendado pela burguesia antiabsolutista, e ilustrado factualmentepelas revoluções manufatureira, na Inglaterra (século XVII e XVIII),e a de caráter social e político, na França em 1789 (século XVIII). Fundamentado na ciência neutra, são subvertidas asordensrepousadasnos preceitos feudais e clericais que emitiam o juízo de valor da propriedade feudal, das coisas e da sociedade, segundo um obscurantismo metafísico.Quanto àeconomia, consolidam-se os princípios da liberdade individual e do liberalismo econômico calcados na metáfora da "mão invisível”, que norteiam o constructo do equilíbrio de mercado.O segundo recorte histórico localiza-seno decorrer do século XIX e apresenta-se como uma ideologia conservadora. Seus fundamentosdecorrem da identidade entre a sociedade e a natureza, que expressa:1) a "homogeneidade epistemológica" das ciências natural e social;2) a coisificação dos fatos sociais; 3)uma sociologia funcionalista que associa a sociedade a um ser vivo.Amparando-se também no axioma da neutralidade, que desconsidera o condicionamento histórico-social, endossa a nova ordem estabelecida baseada na produção industrial.

A discussão positivista foi enriquecida com a presença de M. Weber. Weber se enquadra nesta corrente através de sua démarche, que se constitui mediante um paradoxo inerente, já que esta combina temáticas de caráter historicista e positivista, ou seja, "a sua teoria da Wertbrziehunq das questões(relações com valores - sem caráter universal e absoluto) é de tendência historicista; e sua teoria da Wert-freiheitdas respostas(neutralidade axiomática ou "sem julgamento de valor") é de orientação positivista. (LÖWY, 1987: 36). A concepção de Weber envolve, por um lado, "a não dedução dos valores a partir dos fatos", pois o empirismo não se presta ao julgamento de valor, inexistindo uma verdade puramente empírica da realidade; e, por outro lado, “a não dedução dos fatos a partir dos valores", partindo do princípio de que o ponto de vista de valor determina a questão da investigação, mas seus resultados são neutros. Isto suscita uma discussão sobre a ascendência entre o valor normatizado fundado na história, cultura e sociedade afim com a concepção de região sujeito; e a unicidade das leis naturais e sociais, resultando na neutralidade de ações objetivas afim com a concepção de região objeto.

O historicismosurge nos fins do século XVIII como um movimento conservadoraos fatos progressistas da época - iluminismo, revolução francesa, ordem burguesa, industrialismo, etc. -, com o fim de preservar o direito feudal. SegundoLöwy, a manifestação historicista se deu de formas múltiplas em sua expressãoliterária e política (Schiegel,Görres, Muller), do direito (Savigny), e da então historiografia moderna (Ranke, Droysen, Sybel).As proposições básicas do historicismo são: 1) todos os fenômenos culturais, sociais ou políticos são históricos; 2) há diferenças entre fatos naturais e históricos; 3) a história absorve não só o objetoda pesquisa (o que é pesquisado), como o sujeito (a realidade pesquisada) (LÖWY,1987: 63 e 64).Incorporou a idéia de que a própria história se encontra impregnada 
de valores e crenças e, portanto, é ela que nos permite avaliar e julgar o conhecimento da realidade. Dessa forma, o historiador procede segundo uma ordem natural das coisas que significa o crescimento histórico (orgânico) das instituições, distinguindo-se do positivismo que, interpreta a ordem natural através da harmonia das leis naturais e sociais.

No fim do século XIX aparece uma dimensão relativista do historicismo (W. Dilthey e K. Mannheim), a qual, além de relativizar os acontecimentos históricos, rompe com a visão conservadora, e reage com relação à forma de acumulação do capitalismo industrial, apresentando, portanto, uma postura crítica, evidenciada na seguinte colocação: “ $A$ intelligentsia tradicional não crê mais na manutenção dos estilos de vida pré-capitalista, mas se recusa a aderir ao capitalismo industrial, que é sentido como hostil a seu ser social e cultural; orelativismo está, sem dúvida, vinculado a estes dilemas. ”(LÖWY, 1987: 68).

Dilthey estabeleceu uma leitura básica entre "as ciências do espírito" e "as ciências da natureza", apoiando-se nas características de que o sujeito e o objeto fazem parte de um mesmo universo cultural e histórico eda impossibilidade de se separar o julgamento de fato e de valor. De acordo com Löwy, o seu historicismo é desprovido de uma densidade social, enquadrando seu modelo em épocas históricas ou em culturas nacionais.Quanto a Mannhein, Löwysustenta que, apesar dele ter iniciado sua trajetória filosóficanum idealismo metafísico, verifica-se uma mudança em seu modo de pensar motivada pela influência de Georg Lukács. Ele fez uma abordagem historicista relativista, com a imagem de uma sociologia histórica do conhecimento tingida de marxismo, pois, como coloca Löwy, Mannheinlança suas ideiassobre a "dependência situacional"de todo o conhecimento histórico, em que defende a presença da posição filosóficohistórica do sujeito observador sobre qualquer afirmação histórica, ressaltando-se o vínculo comclasse social.

O marxismo, segundo Löwy (1987: 95 e 96) "foi a primeira corrente a colocar o problema do condicionamento histórico e social do pensamento e desmascarar as ideologias de classe por detrás do discurso pretensamente neutro e objetivo dos economistas e outros cientistas sociais".Dessa forma, torna-se pertinente tratar da questão de Marx quanto à concepção da contradição ou da articulação entre ciência e ideologia no conhecimento social. Nesse contexto, vejamos breves aspectos das dimensões positivista,historicista, racionalistas e stalinistadomarxismo descrito por Löwy.

A dimensão positivistamarcou sua posição no final do século XIX e início do século $\mathrm{XX}$, e visava tratar o marxismo como uma teoria "puramente cientifica", isenta de condicionantes sociais e ideológicos. Os pensadores tinham em comum a influência do axioma da neutralidade e da naturalização das leis sociais, e efetuaram uma crítica, especialmente Bernstein, no que designaram de caráter partidário e tendencioso da teoria de 
Marx. Esta crítica apoia-se no seguinte argumento: Marx “... subordina as exigências científicas a uma tendência”, tornando-se então “... prisioneiro de uma doutrina”, (LÖWY, 1987:111), que seria o fim socialista, impossibilitando-o de atingir uma cientificidade objetiva.Quanto a este aspecto,Kautsky endossa e defende a separação do julgamento de valor do julgamento de fato, pois, para ele, "O marxismo era, portanto,concebido como uma ciência positiva, livre de julgamento de valor; se o ideal socialista (a utopia revolucionária) aparecia em Marx, isso resultava de uma fraqueza humana desculpável, que ele próprio procuraria superar...”(LÖWY,1987: 114).

Hilferding ajustava-se à tese da dissociação entre fatos e valores, bem como Plekhanov, defensor do "método objetivo", retirava do socialismo científico toda a influência normativista do "deve ser", e de "utopia", e de todo elemento "subjetivo". Assim, descaracteriza-se o ponto de vista de classe do marxismo, pois, como coloca Bernstein (apud Löwy,1987: 112), “... a ciência é livre de toda tendência; enquanto conhecimento dos fatos não pertence a nenhum partido ou classe. 'Não obstante, autores como W. Lênin e R. Luxemburg resgatam a essência de Marx, pois introduzem uma démarche não positivista, evidenciando a posição de classe da ciência marxista, pois como expõe Lênin: "em uma sociedade fundada na luta de classe, não poderia haver ciência 'imparcial',.

A dimensão historicista caracteriza-se pela análise dialética da historicidade dos fatos sociais, pois reconhecem de forma explícita as posições de classe (proletariado e burguesia) do marxismo. Segundo Lukács, o conhecimento da sociedade integra as visões, subjetiva (consciência de classe) e objetiva (situação de classe), que definem os limites deste conhecimento. Para o autor, as classes da burguesia e do proletariado, estando integradas no processo de produção capitalista, são as únicas que têm condições de entender o movimento global da sociedade.Goldmann, a partir de Lukács, constituiu uma sociologia diferencial do conhecimento que tem como tese central: "aestrutura categorial da consciência do pesquisador é um 'fato social' que se relaciona comas aspirações e interesses dos diferentes grupos sociais."(LÖWY, 1987: 133). Como implicações desta tese, temos uma crítica quanto à assimilaçãoentre as ciências natural e social feita pelo positivismo. A Ciência Natural se pauta pela universalidade de valores e interesses comuns aos distintos grupos sociais subordinados à

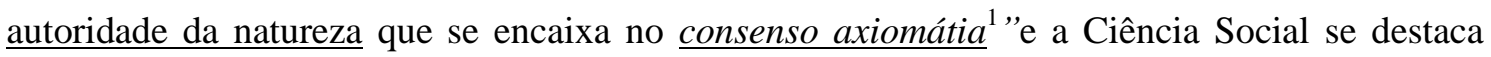
pela falta de consenso, o que reflete as divergências de valores e os diferentes interesses das classes sociais, possibilitando a pluralidade de ideias e de concepções no olhar a sociedade.

\footnotetext{
${ }^{1}$ Para Löwy (1987: 133): “... permite às ciências como a fisica e a química atingir um nível de objetividade elevado e escapar aos constrangimentos e limitações das ideologias sociais."
} 
A dimensão racionalista (Escola de Frankfurt) é analisada por Löwy a partir de um exame da posição desta escola em relação à Teoria Crítica $^{2}$ e aos valores de classe. Uma posição básica desta teoria é o seu antipositivismo, sua oposição à ordem estabelecida, e seu engajamento explícito a certos valores. Para tanto, são abordados os estudos de Horkheimer, Marcuse e Adorno. Quanto a Horkheimer, temos a tese do "livre argumento de valor", que tem a função de servir aos objetivos institucionais da sociedade industrial. Este autor, apoiando-se em um argumento teórico da Razão, era adepto da tomada de consciência correta a partir do indivíduo e de pequenos grupos políticos, pois os conflitos de interesses dos indivíduos na classe social impedem uma tomada de consciência autêntica de classe.

Marcuse situa o marxismo como “. ..a teoria concreta da práxis proletária ...” e, como Lukács, admite que o amadurecimento na definição de sua ação advém da consciência de classe. Apesar de sua influência lukacsiana, algumas convicções de Marcuse se referem a que, segundo Löwy (1987: 145), “... a base 'ontológica' ou 'epistemológica' da Teoria Crítica não é o proletariado (como Lukács), mas a essência humana, negada e oprimida pelo capitalismo.", Adorno, recusando a teoria da objetividade institucional de Popper, e considerando ingênuo o fato de se confiar nas instituições como garantia de acesso à verdade objetiva, defende como fundamento da verdadeira consciência a ordem "ética e racional", pois, rejeitando a ótica positivista de Weber da apreensão do conhecimento livre do julgamento de valor, questiona os valores que são necessários para atingir a verdade objetiva, os quais se situam no âmbito do processo histórico, exigindo-se uma transformação social para a resolução de problemas práticos da sociedade.

A dimensão stalinista se reporta a duas óticas que se integram; uma, de natureza política, e outra, do âmbito da ciência. A primeira trata da formação, na antiga União das Repúblicas Socialistas Soviéticas (URSS), de uma camada social burocrática oriunda do proletariado, a qual, segundo Löwy (1987: 160), é destituída, no sentido marxista, do conceito de classe social, mas trata-se de “... uma 'ordem social (Stand)' definida por critérios político-ideológicos, de formação análoga à ordem clerical das sociedades pré-capitalistas.” Assim, o stalinismo expressa o ponto de vista e os valores da burocracia instituída, que desfigurou a essência do pensamento marxista, visando convertê-la em uma ideologia conservadora como instrumento de dominação da burocracia para se manter no poder.

A segunda ótica envolve a introdução de uma visão positivista ao inverso, pois incorreu na tentativa de ideologização e politização das ciências naturais, definindo assim uma ciência

\footnotetext{
${ }^{2}$ A Teoria Crítica da Sociedade se iniciou com a publicação de Max Horkheimer em 1937, intitulado "Teoria Tradicional e Teoria Crítica". Trata-se de uma teoria que secontrapõe às abordagens de linhagem cartesianas e defende a união das análises teorica e prática.

${ }^{3} \mathrm{O}$ conceito de essência humana tem uma dimensão maior (distintas forças sociais) do que a escolha de uma classe (proletariado) como protagonista dos valores universais. Este conceito é resgatado de Hegel, retomado por Marx, e adotado por Marcuse, que enraíza a Teoria Crítica numa essência (hegeliana) racionalmente definida.
} 
classista (proletária e burguesa). Este fato é naturalmente estranho ao marxismo, já que diz respeito a uma inovação teórica do stalinismo em que Trofim Lyssenko aparece como seu maior expoente. ${ }^{4}$ Este autor foi diretor do Instituto de Genética da Academia de Ciências da URSS a partir de 1940 e suas teses antimendelianas ${ }^{5}$ entraram na agenda da ciência e educação soviéticas ancoradas nas diretrizes políticas e ideológicas da então nomencratura da burocracia do Estado stalinista. Apesar da associação de ambas as óticas (político e ciência), em 1964 esta postura é esgotada, pois segundo Löwy (1987: 165): “... a ideologização das ciências da natureza não era necessidade vital para o 'Stand" burocrático pós-capitalista como era para o 'estado' clerical pré-capitalista",

\section{MODELOS DE OBJETIVIDADE CIENTÍFICA}

Com base na resenhaa respeito das correntes de pensamento positivista, historicista e marxista,formulam-se os modelos de busca da objetividade científica que incorporam uma discussão acerca da relação entre as ciências naturale social, dos fatos e valores, do objeto e do sujeito de análise, e da (im) parcialidade científica. Esses modelos transformar-se-ão em bases de enquadramento para o analista regional, segundo a sua concepção filosófica e a utilização do método de raciocínio e de investigação científica, no sentido deconduzi-lo a constituição de seu “olhar a região"na condição de objeto ou de sujeito de estudo.

A sociedade pré-capitalista baseava-se em normas e posições ideológicas, políticas e de julgamento de valor, as quais estavam inseridas no contexto da metafísica e da cosmogonia.Dessa forma, a análise científica foi influenciada por juízos de valores visando à manutenção da então ordem estabelecida. Com o capitalismo, introduziu-se uma nova ordem social e econômica associada ao positivismo do modelo científico-natural de objetividade, fundamentado nas teses da homogeneidade epistemológica das ciências (natural e social) e da neutralidade axiológica do saber, causando a emancipação das ciências naturais em relação aos condicionamentos ideológicos e clericais da ordem feudal. Diante da abstração dos valores e normas, este modelo pressupõe que o investigador científico e, em particular, o analista que olha a região,adotam uma posição de imparcialidade em sua interpretação e nos procedimentos de

\footnotetext{
${ }^{4} \mathrm{O}$ embate entre as ciências proletárias e burguesas refletiu basicamente o confronto dos Estados durante a guerra fria, vinculando assim a ciência burguesa ao "Estado ou bloco de estados (EUA/Europa Ocidental contra a URSS)", e a ciência proletária aos Estados da esfera da URSS. Dessa forma, a ligação entre as classes sociais e a produção científica ficou subordinada a uma "Ciência de Estado". Em consequência, generalizou-se este embate para outras esferas de atividade da sociedade como a da literatura, arte, música, etc.

${ }^{5}$ Trata-se de Gregor Mendel, considerado o "pai da genética".

${ }^{6}$ Para efeito de ilustração, vejamos a trajetória de Althusser que, como autor marxista com passagem no lyssenkismo, faz em 1965 sua autocrítica, e questiona tanto esta teoria como a ligação da ciência com a luta de classe. Classificado nesta fase, como neopositivista e neo-stalinista, defende a tese da independência da ciência social em relação à luta de classe. Contudo, em 1970, liberta-se desta postura e passa a admitir o ponto de vista da classe proletária como referencial para a apreensão da objetividade científica.
} 
sua intervenção. Com base nesses atributos, associa-seeste modelo às percepções do método dedutivo de investigação científica e do "olhar a região" como um objeto da pesquisa.

Dianteda consolidação da sociedade industrial capitalista e o aparecimento dos conflitos de classes e juízos de valores, um novo modelo de interpretação da realidade é colocado na agenda. Trata-se do modelo científico-social de objetividade que também resultou do pensar a história em sua versão relativista historicista e marxista historicista. A interpretação do modelo requer comentários a propósito do relativismo, o qual estabelece que todo o conhecimento érelativizado, segundo os valores de uma classe social em certo momento histórico, assim como uma leitura marxista no que tange a maior ou menor intensidade no uso da categoria "luta de classe".Ressalta-se que esse modelo apoia-se em princípios normativista, já que o juízo de valor do investigador e analista regional se posiciona na forma de interpretar e de intervir na região, de tal maneira que o"olhar a região"venha a ocupar o lugar de sujeito.

Nessa discussão referente às questões científico-natural e científico-social, Löwy apresenta outra via de interpretação em que supõe a presença de um "espaço cognitivo intermediário"entre as ciências naturais e sociais, pois, embora rejeitando a hipótese da homogeneidade, não reconhece a existência de uma divisão estanque entre estas ciências. Este posicionamento está ancorado no fato de que os interesses de classes definem a seleção do objeto da pesquisa e a aplicação de suas descobertas (caráter não-positivista), mas não afeta, no âmbito da ciência natural, a essência das descobertas científicas que caracterizam a verdade objetiva da realidade. Esta interpretação é posta apenas com parte da resenha do livro de Löwy, não sendo objeto de estudo neste artigo.

O esboço dos modelos de objetividade científica, e à reflexão sobre a apreensão dos fatos a partir dos valores, e vice-versa,nos remetepara ométodo de investigação científica, assunto que é abordado através de concepções dos métodos filosóficos e das metodologias de investigação da ciência.

\section{MÉTODOS: FILOSÓFICOS E PESQUISAS CIENTÍFICAS}

Esta seção aborda a integração entre a filosofia e a ciência tendo como centro o método de percepção da realidade. Dado que a filosofia, ao por em relevo a sapiência, configura-se como um reservatório do conhecimento protagonizado pelas ciências. A seguir,elabora-se uma síntese da filosofia e seus métodos de investigação científica como bases contextuais que permeiam as percepções do pesquisador.

Em se tratando de filosofia, que se origina das palavras gregasphilos (que ama) + Sophia (sabedoria), significando "amor à sapiência", vejamos uma definição que bem esclarece este 
termo no sentido de descartar a idéia de que filosofar é fazer reflexão do pensamento desvinculada da realidade concreta da sociedade. Essa definição consta em livro,que veicula as aulas de filosofia de Politzer, ${ }^{7}$ esclarecendo o filosofar da seguinte maneira: “... concepção geral do mundo da qual se pode deduzir certa forma de conduta. ”(BESSE \& CAVEING, 1954: 14). É com base nesta definição que se adota o raciocínio deste artigo no trato do "olhar a região", pois as estratégias de intervenção do analista regional dependem da sua concepção formada, segundo o enquadramento de sua percepção nos modelos científicos (natural ou social) de objetividade.

A filosofia se expressa basicamente pelo seu caráter "materialista e idealista". O "materialismo" define como elementos determinantes a matéria e o ser, e como derivados a consciência e o pensamento. Esta filosofia defende a possibilidade de se conhecer e explicar a existência do mundo com seus fenômenos a partir do movimento da matéria. O "idealismo" parte do conceito de idéia, espírito e consciência, para determinar a realidade material, negando a possibilidade de explicar objetivamente o mundo.Apresentam-se dois métodos filosóficos de caráter universal e antagônico (dialético e metafísico), os quais são utilizados em todos os setores do conhecimento.

O método dialético ( "dialegein" = discutir) dominava a antiga filosofia, na qual pontifica o pensador Herácrito, pois como é citado por Siussiukálovet alii (1986: 16), "um mesmo elemento em nós está vivo e morto, jovem e velho, encontra-se no estado de sono e de vigília". Entre outros autores dialéticos podemos destacar Hegel como um dos principais formuladores deste método no âmbito da filosofia "idealista". Marx e Engels, embora reconhecendo os fundamentos científicos da dialética hegeliana, rejeitam seu caráter idealista e subjetivista do mundo e introduzem uma visão objetiva baseada no caráter "materialista" da filosofia de Feuerbach. Esses autores apoiam-se em bases objetivas de fatos materiais e do momento sociopolítico e histórico, implicando na aplicação da "lógica dialética" à sociedade capitalista com a revelação das identidades das classes sociais (capitalista e trabalhadores), que expressam através de suas relações dinâmicas as bases para a reprodução econômica do capital. Esta interpretação difere da "lógica clássica", que apreende as coisas de forma absoluta e fechada em si mesmas, respaldando a ideia da existência de uma posição relativa de segmentos da sociedade que evidencia a não identidade ou negação da essência de classes sociais.

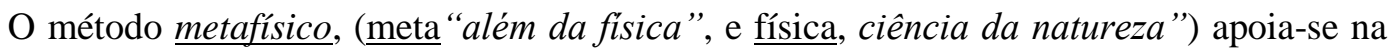
posição doutrinária de Parmênides (com teses do tipo: ser uno, estático, eterno, sensibilidade como ilusão, e o que se vê não é confiável.),que, segundo Siussiukálov et alii (1986, p. 16), “... ensinava que o ser concebível pelo intelecto é invariável, imóvel e uno ...”. Assim, este método

\footnotetext{
${ }^{7}$ Georges Politzer, psicólogo e filósofo marxista de origem húngara e radicado na França, que atuou na resistência francesa contra os nazistas, sendo fuzilado em 1942.
} 
ancora-se na imutabilidade e na realização em definitivo das coisas, afastando qualquer relação de reciprocidade e de causa e efeito. Para Aristóteles, o objeto da metafísica corresponde ao estudo do ser que se situa além da natureza física, pois enquanto esta se fundamenta no movimento, o ser do além é imutável e eterno. Dessa forma, este método de raciocínio filosófico desconsidera a visão de processo de transformação do mundo, pois se contrapõe aos conceitos de movimento e mudança, em favor do repouso e do idêntico. Um outro aspecto dessa posição se reporta à separação das coisas e à negação dos contrários, como bem coloca Politzer, nesta citação: “... uma coisa é, ou bem isto, ou bem aquilo. Ela não pode ser ao mesmo tempo isto e aquilo...." (BESSE \& CAVEING, 1954: 26 - 27). Este aspecto está fundado na lógica clássica, que na procura da natureza e essênciada identidade absoluta das coisas, transcende para uma explicação externa às relações dos fatos sociais e naturais.

A metodologia da ciência, ancora os métodos de pesquisas que definem as suas imagens e consistências de suas descobertas e afirmações.A compreensão da investigação científica envolve a correlação da pesquisa em nível empírico e teórico. Apesar da existência de posturas exclusivistas defendidas por adeptos dos métodos indutivos ou dedutivos, coloca-se a questão da dependência recíproca do aparelho teórico com a experiência, pois como afirma Siussiukálovet alii (1986: 69), "os fatos estabelecidos mediante experimentação são explicados de uma forma racional pela teoria; é também uma teoria que revela as leis da sua existência do seu desenvolvimento."

A pesquisa empírica parte do concreto para o abstrato baseado no método indutivo. A indução, tendo a observação e a experimentação como instrumentos de estudo, apreendem os fatos empíricos para a percepção do real, situando-se numa análise metodológica à posteriori. A pesquisa teórica, partindo do abstrato para o concreto, apoia-se no método dedutivo, o qual consiste em uma percepção global de apreensão das partes, situando-se na análise apriorística. Ambos os métodos devem ser tratados na investigação científica de forma interativa, pois, resgatando Mill (1984: 226 - 29) e seu "Sistema de Lógica", quando aborda o método dedutivo, enfatiza que esta associaçãoconsiste em três operações que formam a lógica da pesquisa: indução direta, raciocínio e verificação. A indução torna-se a base de tudo, e na exposição de Mill temos que, “... embora em muitas pesquisas particulares a indução possa ser substituída por uma dedução anterior; mas as premissas dessa dedução prévia devem ter sido estabelecidas pela indução.". O raciocínio envolve a apreensão dos efeitos produzidos pela combinação das leis que regem as causas dos fenômenos captados pela indução direta. A verificação, que trata da contra prova da aplicação do método dedutivo, pois como coloca Mill, "Para que as conclusões obtidas por dedução sejam garantidas, é preciso que, cuidadosamente comparadas, estejam de acordo com os resultados da observação direta em 
qualquer lugar que se possa constatá-la." Assim, a indução e a dedução estão indissoluvelmente ligadas no processo dialético do conhecimento.

$\mathrm{Na}$ ciência econômica, as posições metodológicas da indução e dedução encontram-se vinculadas em várias correntes teóricas. As escolas (neo)clássicas e austríaca, fundadas em uma visão positivista, abstrata, dedutiva e racionalista, visa apresentar a realidade como ela é de fato. Esta teoria tem uma articulação lógica da dedução de princípios e leis gerais passíveis de aplicação à realidade empírica. A escola histórica alemãse fundamenta no método indutivo, na influência histórica, numa abordagem interdisciplinar e numa concepção normativa. Uma distinção entre essas escolas refere-se, segundo Bianchi (1992: 136), "a pendência entre dedução e indução como fonte de conhecimento científico, entre o chamado método 'a priori' e o método a posteriori., "É neste contexto, que John Neville Keynes critica a separação dos métodos através da "falácia do método exclusivo", pois baseado no argumento da pluralidade das causas dos fenômenos práticos de Mill (1984), defende a combinação de ambos os métodos como forma de desenvolvimento da ciência.

Diante dos modelos de objetividade científica, dos métodos filosóficos e de investigação científica, a próxima seção se encarrega de fazer uma reflexão sobre "o olhar a região", visando posicionar o analista regional segundo as categorias de região objeto ou sujeito.

\section{O OLHAR A REGIÃO}

Sendo a "região" o objeto central deste artigo, contextualiza-se a diversidade de interpretações nos estudos da Geografia. Nos seus primórdios a geografia - do Grego os termos geo (terra) + graphein (escrever) o estudo da superfície do planeta terra- se preocupou em descrever as paisagens físicas. Período em que a disciplina esteve voltada para a descrição e a compreensão da realidade material e da geografia, tal que, do ponto de vista físico-geográfico, o "espaço" é definido a partir das características naturais do meio físico. Esta visão já foraobjeto de reflexões de filósofos da antiguidade, a exemplo de Lucrécio (1973) através de seus escritos "Da Natureza". Diante da realidade composta por pessoas que se constituíramem grupos e, consequentemente estabeleceram uma sociedade organizada, outros elementos apareceram, os quais por sua vez, motivaram os estudos inerentes às relações do homem com a natureza, possibilitando às análises da localização, do bem estar da população com o seu território geográfico e com o meio ambiente, e da regionalização do espaço. Dessa forma, faz-seuma breve leitura da geografia e da contribuição de alguns autores vinculados à mesma, mas tambémidentificados com a economia regional.

Uma primeira leitura envolve a "Geografia Clássica", que se consolida como ciência no século XIX mediante duas clivagens influenciadas por estágios econômicos e políticos distintos. 
Uma primeira clivagem, ambientada na Alemanha com os seus propósitos de império e de unificação territorial sob a égide de Bismarck, deu origem à busca do espaço vital (Lebensraum). Dentre seus principais autores destacam-se Von Humboldt e Friedrich Ratzel com as suas visões do "determinismo geográfico". Quanto à economia regional têm-se os teóricos clássicos da localização, de linhagem determinística, a saber: Von Thünen, com sua abordagem do Estado isoladoque trata dos anéis de localização e da homogeneidade da fertilidade na terra; Alfred Weber e seu estudo da localização industrial, ancorado nos custos de transportes, de mão de obra e no efeito aglomeração; Walter Christaller, com a sua teoria dos lugares centrais e August Löch, com as redes de cidades e o seu modelo de equilíbrio geral hexagonal localizado; além de vários outros pensadores.

A segunda clivagem conhece sua gênese na França durante a terceira República (1871 a 1940) e seus conflitos com a Alemanha. Os propósitos franceses, no estágio tecnológico em que se encontravam, visavam à interferência na paisagem de seus domínios territoriais mirando seu desenvolvimento econômico. Oautor principal vinculado a esta posição é Vidal de La Blache, que introduz a visão do "possibilismo geográfico", sendo referência para as reflexões deste artigo. Por outro lado, outros estudiosos franceses após os anos de 1940, consagrados na economia regional são: François Perroux e Jacques Boudeville, que contribuem com tipologias de espaço e de região "homogênea, polarizadae de planejamento". Acrescenta-se a esta visão autores de outras nacionalidades que pensaram o desenvolvimento regional e que compuseram o movimento da "economia do desenvolvimento", entre os quais podemos citar R. Rodan, R. Nurkse, A. Lewis, A. Hirschman, G. Myrdal, e tantos outros.

Uma segunda leitura passa pela "Nova Geografia" ou "Geografia Teorética", que se tornou conhecida no pós II Guerra Mundial e apresenta uma abordagem ancorada em modelos matemáticos de perfil neopositivista. Originária da escola anglo/saxônica, e em busca de umstatus de ciência precisa, resgata o positivismo como base para a unicidade entre as ciências natural e social. Como bem coloca Christofoletti (1985: 1 - 6), "A abordagem da geografia científica está baseada na observação empírica, verificação de seus enunciados e na importância de isolar os fatos de seus valores. Ao separar os valores atribuídos aos fatos dos próprios fatos, a ciência procura ser objetiva e imparcial." Schaefer (1953), um dos primeiros pensadores dessa abordagem em geografia, introduz a estatística e os métodos quantitativos nos estudos geográficos em defesa de um maior rigor metodológico. De acordo com Ruiz (2003), autores contemporâneos como P. Krugman, M. Fujita e A.Venables estão entre os mais importantes representantes da Nova Geografia Econômica (NGE) e sãoassociadosna esfera dos estudos da economiaregional e afim com a Geografia Teorética. 
Uma terceira leitura remete à "Geografia Crítica", que surgiu nos anos de 1970, inicialmente na França, mas difundida também na Itália, Alemanha, Brasil e em vários outros países, bem como em sua versão marxista denominada de "Geografia Radical", que surgiu na Inglaterra e difundiu-se nos Estados Unidos. Ambas as versõesrenovaram o pensar a Geografia, pois com o uso do método dialético reagem às teses de base metafísica da Geografia Teorética. Rompendocom o preceito da neutralidade da ciência e dos supostos positivistas, introduzem um conteúdo qualitativo aos estudos geográficos com a adoção de teses normativas fundadas nos valores e práticas de caráter social, econômico e político. De acordo com Moura R. et alii (2008), esse movimento em seu nascedouro interagira com outras áreas disciplinares (economia, sociologia, história, antropologia, etc.) e com intelectuais do porte de H.Lefebvre,L.Althusser,C.Bettelheim, e outros.Entre os principaisexpoentesdaversão crítica têm-se, por exemplo, Y.Lacoste, que trata a geografía do subdesenvolvimento e Pierre George que considera naanálise regional tanto os atributos do modo de produção capitalista, como os fundamentos históricos da realidadegeográfica,estabelecendo-seumelo entre passado e futuro. Naversãoradical,faz-se referencia como relevantes,D. Harvey, que com a sua leitura marxista exalta a prática social para se pensar a categoria espaço, e M. Santos em defesa de sua geografia cidadã e de sua interpretação do espaço a partir de seus sistemas de objetos e ações. ${ }^{8}$

Com relação ao "olhar a região" pelo pesquisador e como é definido a sua forma de intervenção, adotam-se neste artigo duas leituras conceituais de região: uma, que espelha um recorte territorial fruto de uma definição institucional que é compatívelcom a abordagem físico-geográfica; outra, como resultado de uma prática social em que se consideram suas histórias, práticas socioeconômicas, suas culturas e outros atributos relativos a uma formação social. Baseando-se nas percepções de região, a categoria "regionalização" envolve a construção de regiões a partir da escolha de critérios compatíveis com os objetivos das institucionalizações administrativas, estando, dessa maneira,baseada na Geografia Clássica; ou a partir dos fundamentos de sua história e prática socioeconômica, por conseguinte, associada aos ensinamentos das versões crítica ou radical da Geografia.

Diante do "possibilismo geográfico", o homem é colocado em uma posição ativa em relação à natureza, requerendo-se doanalista regional a percepção da realidade através das relações entre valores e fatos, que devem nortear a qualidade da intervenção econômica sobre a natureza. É, portanto, neste contexto que se pode focar o "olhar a região", a partir de concepções filosóficas do pesquisador que podem estar associadas a um dos métodos aqui discutidos, a saber, o dialético ou o metafísico. Dessa forma, é viável elaborar uma interpretação da realidade

\footnotetext{
${ }^{8}$ Percepção de "espaço" a partir de construções materiais baseados na evolução do conhecimento humano e de padrões históricos de tecnologia, em contraponto, com a existência de artefatos naturais.
} 
em estudo condicionada por referências históricas e sociais ou vinculada às leis físicas e químicas da natureza, compatibilizada com os modelos científicos de objetividade social ou natural, respectivamente. Com esses esclarecimentos e definições, que condicionam o analista regional na condição de agente; a região pode ser encarada do ponto de vista de um simples objeto de investigação ou como o sujeito de sua história econômica e social. Neste sentido, pode-se definir o método de investigação científica, o qual é factível associar à pesquisa sobre uma região, mediante o emprego dos vieses dedutivo ou indutivo e apoiado nas visões de região objeto ou sujeito, respectivamente.

Segundo Boisier (1996), em épocas remotas da história havia as "regiões naturais" que correspondiam à fase da ausência e da intervenção do homem sobre a natureza física. Em outro momento histórico apareceram as "regiões equipadas" resultantes de algum tipo de ação humana criando equipamentos físico-geográficos, e efeitos inerentes à visão possibilista da geografia. Tradicionalmente, a percepção do agente econômico sempre comportou um "olhar a região" como um "objeto" de análise e intervenção. Atualmente, a escala regional resulta de princípios organizativos e institucionais que assumem a forma de uma "região organizada", a qual considera em sua delimitação atributos que refletem ahistória, acultura, oshábitos e costumes, as crenças, e ospadrões demográficos e socioeconômicos. Este tipo de região leva o agente e analista regional a olhá-la como sujeito de sua própria historia.

Em relação à"região organizada"olhada como "sujeito", Boisier (1994) faz uma análise a partir de pelo menos duas dimensões: a contextual e a estratégica. Do ponto de vista "contextual", enfatiza os processos de abertura externa e interna da região, respectivamente, no atual mundo globalizado com seus preceitos econômicos e na descentralização de ações norteadas por processos da política. No tocante à abertura externa, o "olhar a região"temsido incentivadapara a prática de integração regional inclusive em caráter supranacional, ao tempo em que novos atores locais e regionais definem as capacidades de competição por capital, tecnologia e mercados. Quanto à abertura interna, a sustentação da descentralização política abarca as atualizações científicas e tecnológicas, refletidas em processos de fragmentações de empresas e de lugares. Adita-se a esses aspectos a autonomia dos atores locais da sociedade civil, fortalecendo a descentralização sociopolítica e econômica.

A dimensão "estratégica" é baseada na revolução científica e tecnológica, que induz o "olhar a região" para novas configurações e gestão regional ancoradas em bases institucionais endógenas em consonância com o mundo globalizado. Tal visão é moldada pela capacidade da região em se adaptar às mudanças que se impõem tendo em vista a integração com o mundo externo, e pela capacidade da mesma em gerar e preservar sua identidade sócio-histórica e institucional presentes na região organizada. No âmbito endógeno desta região faz-se necessário 
uma composição com três atributos: a "velocidade", que permite ter acesso e aproveitar as oportunidades do mundo competitivo; a "flexibilidade", que exige adequação a escalas e estruturas econômicas distintas; e a "maleabilidade", que se prende à capacidade da região de se moldar com rapidez às mudanças do ambiente competitivo.

Coma visão possibilista da geografia, permite-se fazer considerações sobre as categorias de "região objeto" e "região sujeito". A região objeto é olhada de fora, diga-se, de forma exógena. Uma vez definidos os propósitos para a regionalização de um dado espaço, institucionalizam-se, em primeiro lugar,as demarcações administrativas das escalas regionais. Este posicionamento do pesquisador imbuído de uma racionalidade instrumental parte do princípio de que a intervenção econômica é decidida estritamente em função do interesse do agente econômico externo à região. Trata-se de ações em que se considera a região como mais um instrumento no processo de produção, resultando em uma regionalização exógena e, por conseguinte, a formação da "região objeto". Esta visão vincula-se às percepções que abstraem os valores e normas e incorpora as teses positivistas da homogeneidade epistemológica das leis natural e social, e da neutralidade axiomática das ações dos agentes econômicos sobre a região.

A "região sujeito" é olhada de forma endógena. No processo de regionalização são levadas em conta as pessoas, a sociedade, a história e a cultura social, implicando, como condição para a delimitação regional, a identificação da identidade local. Dessa forma, a institucionalização administrativa da região se apresenta após a sua formação, refletindo os valores da sociedade local influindo fortemente nas decisões de intervenção do agente econômico, caracterizando a região como o sujeito de sua própria história. Este olhar permite que se preservem características do passado através de certas rugosidades vinculadas à estética, à arquitetura física, à paisagem, e aos fundamentos históricos, sociais e étnicos; sem que com isto se evite a introdução de preceitos contemporâneos. Esta percepção incorpora os juízos de valores e os procedimentos normativos das múltiplas dimensões da sociedade local no olhar do agente econômico como precondição para a definição de formas e estratégias de intervenção na região.

Nesse contexto, a geografia de Milton Santos associada com a região sujeito ou organizada, levanta algumas reflexões sobre as categorias indissociáveis de "espaço e tempo" e de seus sistemas de objetos, possibilitando as interpretações sobre conceitos de paisagens, espaço construído, rugosidades, redes, escalas, etc. O conceito de rugosidade, segundo Santos (1978), se refere a "espaço construído, o tempo histórico que se transformou em paisagem", refletindo a realidade histórica do estágio técnico e do então modo de produção, caracterizandose por "objetos do passado que permanecem e servem ao presente." (CAMPOS, 2008: 156 157). A leitura pós-moderna de Doreen Massey relativa à categoria "lugar" apresenta uma singularidade conceitual em relação à idéia de região demarcada. No entanto, contém alguma 
similitude com a região sujeito quando trata da idéia de "compressão tempo-espaço", associando-se ao movimento e comunicação das pessoas que incorporam as dinâmicas do capital, dos grupos sociais, dos gêneros e raças das pessoas, das diversidades e dinâmicas dos lugares, etc. Transcende a endogenia de sua história e introduz a idéia de lugares extrovertidos "que inclui uma consciência de suas ligações com o mundo amplo, que integra de forma positiva o global e o local." (MASSEY, 2000: 184).

Nota-se que "o olhar a região" pelo analista regional é induzido pela sua compreensão da realidade, que reflete suas concepções filosóficas. Dessa forma, a sua busca do saber e do conhecimento da natureza e da sociedadeé compatível com os modelos científicos de objetividade natural ou social, respectivamente.

\section{CONSIDERAÇÕES FINAIS}

O artigo abordou distintas percepções do analista regional no "olhar a região", segundo os pontos de vistas exógeno da região objeto e endógeno da região sujeito. Foi feito um esboço epistemológico da ciência e uma descrição do estudo dos métodos de raciocínio filosófico vinculados com as técnicas de investigação científica. Formularam-seos modelos de objetividade científica, caracterizando o debate e o embate entre as clivagens positivistas e normativas. A "região" é contextualizada de forma sucinta por meio das leiturassobre as geografias em suas versões clássicas, nova geografia ou teorética,crítica e radical. As interpretaçõesda categoria "região" envolveram duas concepções.

Uma compatível com o "modelo científico natural de objetividade" afeito, no âmbito da filosofia, ao método metafísico de posições positivistas ancoradas nos axiomas da neutralidade do saber e da identidade das leis natural e social. Em relação à investigação e pesquisa, vinculase a uma percepção mais voltada aos atributos das escolas econômicas de base clássica ancoradas na concepção apriorística do método de investigação dedutivo, caracterizandosecomo um ente estático, passivo e neutro, associando-se ao conceito de região objeto.

Outrafica associada ao modelo "científico social de objetividade" que em relação ao método filosófico, vincula-se ao raciocínio dialético que parte da dinâmica endógena a região ancorada em sua identidade histórica e nível de organização da sociedade.Quanto ao método de investigação científica, apoia-se na percepção indutiva da realidade que tem sua origem na escola histórica alemã, tendo como âncora uma visão de análise a posteriori. O fator interior sendo referência para as intervenções sobre a região evidenciam-se os elementos que se relaciona com o ponto de vista de região sujeito. 
Duas questões foram colocadas na introdução sobre a concepção do "olhar a região" que requerem algumas considerações, segundo os conceitos de região objeto e sujeito.

A primeira trata do desenvolvimento assimétrico entre as regiões, dado que tradicionalmente sempre foi interpretada como objeto de intervenção. $\mathrm{O}$ agente e analista regional, imbuído de suas posições positivistas consideram a ambiência interior da região como estática e neutra. Dessa formaas decisões de intervenções são teóricas, dedutivase definidas de forma exógenas a região objeto, pressupondoque seus resultadosprimam pela neutralidade de interesses, sendo comuns e geradoras de efeitos similares para qualquer região. No entanto, constatam-se desníveis de desenvolvimento econômico e social entre regiões, o que sedeve a exclusividade de resultados de distintas eficiências técnica e econômica dos projetos de intervenção, o que é intrínseco a lógica da acumulação do capital, provocando assimetrias regionais.

A segunda situa-se na realidade atual associada a um novo "olhar a região" e que se baseia na aplicação de novas tecnologias.É sabido que no mundo contemporâneo palavras como diversificação, fragmentação e especialização têm-se norteado a variadas análises focadasna economia e, especialmente, nas análises regionais. Dessa forma, observa-se que em razão das novas configurações tecnológicas, econômicas e sociais, e de novas formas na regulação e acumulação do capital,têm ocorrido substanciais mudanças na qualidade das relações institucionais e sociais, exigindo-se que cada região esteja organizada. Em face da existência de diferentes histórias, culturase relações sociaisentre regiões, há distintos padrões de evolução fazendocom que os projetos de intervenção do agente econômico sejam resultados de parcerias entre a eficiência técnica e econômica com os interessesendógenos da sociedade consonante com a sua história e cultura, o que reduzem possíveis assimetrias intrarregional e inter-regional.Dessa forma, faz-se necessário que o agente e analista regional estejamimbuídos de decisões empíricas e indutivas ancorada em um olhar endógeno que é compatível com o conceito de região sujeito.

$\mathrm{O}$ artigo visou instigar o leitor no sentido derefletir sobre a atuação do analista regional em relaçãoao seu "olhar a região" objeto ou sujeito, segundo a sua concepção filosófica associada à adoção dos métodos de raciocínio e de pesquisa.

\section{REFERENCIA BIBLIOGRAFICA}

BeSse, Guy; CAVEIng, Maurice. Politzer, Princípios fundamentais de filosofia. São Paulo: Ed. Hermus. 396p., 1954.

BIANCHI, Ana M. "Muitos métodos é o método: a respeito do pluralismo".Revista de Economia Política, São Paulo 12(2), abr./jun, p. 136 - 42, 1992. 
BOISIER, Sérgio. “Crisis y alternativas en los processos de regionalización”. Revista de la CEPAL. Santiago de Chile, (52), abr., p. 179 -190, 1994.

BOISIER, Sérgio. "Em busca do esquivo desenvolvimento regional: entre a caixa-preta e o projeto político". Planejamento e Políticas Públicas. Brasília: IPEA, N. 13, 1996.

CAMPOS, Rui R. de. “A natureza do espaço para Milton Santos”Geografares, Vitória: UFES,n 6, p. $155-165,2008$

CHRISTOFOLETTI, Antônio. Perspectivas da Geografia.São Paulo: Difel, 1985.

KEYNES, John Neville. The Scope and Method of Political Economy. New York: Kelley\&Millman. 248p., 2009.

LÖWY, Michael. As aventuras de Karl Marx contra o Barão de Munchhausen. São Paulo: Ed. Busca Vida. 210p., 1987.

LUCRÉCIO, Tito C. Da natureza.São Paulo: Ed. Abril Cultural, Os Pensadores, 1973.

MASSEY, Doreen. “Um sentido global do lugar”. In: ARANTES, Antônio A. (org). O espaço da diferença. Campinas: Papirus, 2000.

MILL, John Stuart.Sistema de lógica dedutiva e indutiva e outros textos. São Paulo: Abril Cultural. Os Pensadores, 1984

MOURA, Rosa et alii. "Geografia crítica: legado histórico ou abordagem recorrente"? Revista Bibliográfica De Geografía Y Ciencias Sociales. Universidad de Barcelona, Vol. XIII, n 786, 5 de junho de 2008. Consulta 20/10/2014: http://www.ub.edu/geocrit/b3w-786.htm

RUIZ, Ricardo Machado. A nova geografia econômica: um barco com a lanterna na popa?Belo Horizonte: Texto para discussão N. 200, UFMG/Cedeplar, 2003. 21p.

SANTOS, Milton. Por uma geografia nova: da crítica da geografia a uma geografia crítica. São Paulo: HUCITEC/EDUSP, 236 p., 1978.

SCHAEFER, Fred K. "Exceptionalism in Geography: A Methodological Examination".Annals of the Association of American Geographers, Vol. 43, No. 3. p. 226 -249, Sep., 1953.

SIUSSIUKALOV, et alii. Fundamentos metodológicos e métodos do estudo da filosofia. Moscovo, Edições Progress. 155p., 1986. 